\title{
EXPRESSÕES ATRIBUTIVAS DE CAPACIDADE: MODALIZADORES DEÔNTICOS?
}

\section{Léia Cruz de Menezes ${ }^{\star}$}

Resumo: Este artigo tem por objetivo discutir o papel do uso de expressões atributivas de capacidade como recurso de modalização deôntica na construção da persuasão em discursos políticos. Para tanto, rediscutiremos a modalidade chamada "dinâmica", que se soma aos dois tipos básicos de modalidade: epistêmica e deôntica, em face da análise de como expressões atributivas de capacidade funcionam em discursos efetivamente realizados. Intentamos, assim, contribuir para uma maior clarificação do processo argumentativo, colaborar para a expansão do que se concebe como expressão da modalidade deôntica e cooperar para o entendimento do elo existente entre modalidade deôntica e construção discursiva.

Palavras-chave: Modalidade deôntica. Discurso político. Persuasão.

\section{Introdução}

Este artigo é fruto de uma pesquisa, em andamento, que tem por objetivo analisar o uso de expressões lingüísticas deonticamente modalizadas na construção da argumentação política em discursos proferidos na Câmara dos Deputados, considerando, integradamente, aspectos sintáticos, semânticos e pragmáticodiscursivos. Dentre os vários objetivos de nossa pesquisa, um deles é verificar em que medida trechos atributivos de capacidade, em contexto que nos permita seu entendimento como recurso de modalização deôntica, estão a serviço da construção da persuasão em discursos políticos. Compartilhamos, por meio deste artigo, algumas de nossas ponderações com o público interessado.

Mestranda em Linguística da Universidade Federal do Ceará (UFC/Bolsista FUNCAP). 


\section{Paradigma teórico-metodológico}

A opção por uma abordagem funcionalista é motivada fundamentalmente pelo fato de os objetivos e as hipóteses do presente trabalho terem como enfoque central as funçōes a que se presta o uso de expressões atributivas de capacidade como recurso à construção da persuasão em discursos políticos. Assim, nada mais coerente do que a adoção de um modelo gramatical que se propōe analisar a relação sistemática entre as formas e as funções em uma língua, no qual as funções das formas lingüísticas desempenham papel predominante.

$\mathrm{Na}$ perspectiva funcionalista, as línguas naturais são instrumentos de interação social. Desta feita, o estudo do sistema deve fazer-se dentro do quadro do uso, sendo a descrição das expressões capazes de fornecer dados para a descrição de seu funcionamento em um dado contexto. As prioridades são, obviamente, da pragmática à sintaxe, via semântica (DIK, 1989, 1997). A incorporação da pragmática na gramática postulada pelo funcionalismo torna possível o estudo que intentamos realizar, haja vista ser nosso objetivo a investigação das relações de base funcional entre expressões atributivas de capacidade como recurso de modalização deôntica e a construção da argumentação no discurso político.

Na visão funcionalista, segundo Halliday (1973, p. 14), a noção de "função" não se refere aos papéis que desempenham as classes de palavras ou os sintagmas dentro da estrutura de unidades maiores, mas ao papel que a linguagem desempenha na vida dos indivíduos, servindo a certos tipos universais de demanda, que são muitos e variados. É exatamente esse sentido de propósito sóciocomunicativo que vamos utilizar na análise do uso de expressões atributivas de capacidade, como recurso de modalização deôntica, que se prestam à construção da persuasão em discursos políticos.

No que concerne à descrição lingüística empreendida pela perspectiva funcionalista, esta năo se limita à estrutura da sentença, 
pois considera que uma descrição da estrutura sentencial seja insuficiente para determinar o som e o significado da expressão lingüística. Entende que a descrição completa precisa incluir referência ao falante, ao ouvinte e a seus papéis e estatuto dentro da situação da interação determinada socioculturalmente. E esse é o tipo de descrição que nos interessa, daí nossa preocupação com a identificação e caracterização do lugar enunciativo do qual o orador profere seu discurso; nosso interesse em entender o modo como o orador subdivide seu auditório heterogêneo, de modo que possa dirigir-se a partes selecionadas deste; nosso cuidado com a contextualização sócio-histórica de proferimento do discurso etc., pois, somente assim, será possível compreender o modo de funcionamento das expressões lingüísticas em discursos efetivamente realizados.

\section{A opção pelo modelo de Gramática Funcional de Simon Dik}

Dentre as propostas funcionalistas de análise dos fenômenos lingüísticos (HALLIDAY, 1985; THOMPSON, 1987; GIVON, 1995), embasar-nos-emos no modelo de interação verbal proposto por Dik (1989). Trata-se de um modelo bastante elucidativo das relações intersubjetivas do processo de enunciação. De acordo com o modelo de Dik, a expressão lingüística (enunciado) produzida pelo falante se faz em função: da intenção que ele tem; de sua informação pragmática; e da antecipação que ele faz do que pode ser a interpretação do ouvinte. A informação pragmática do falante e do ouvinte, no momento da interação verbal, é compreendida como sendo um conjunto completo de conhecimento, crenças, suposições, opiniões e sentimentos. Fica claro, assim, que o termo "informação", de modo algum, restringe-se ao conhecimento intelectual do indivíduo, mas inclui qualquer item presente em seu "mundo mental" - crenças e preconceitos, por exemplo.

Na outra direção, a interpretação do ouvinte se faz cm função de uma expressão lingüística; da informação pragmática 
dele; e da recuperação que ele faz da intenção comunicativa do falante. A expressão lingüística é, assim, mediadora da relação que se estabelece entre falante e ouvinte. Desse modo, o significado que é codificado pelo falante na expressão lingüística não é idêntico a sua intenção e, da mesma forma, não se iguala à interpretação final a que chega o ouvinte; o conteúdo semântico representa, então, a informação necessária que corresponde, sistematicamente, a determinadas intenções para determinadas interpretaçōes, dentro da estrutura definida pela informação pragmática disponível ao falante e ao ouvinte.

Da perspectiva do falante, há sempre a intenção de provocar alguma modificação na informação pragmática do ouvinte e, para tanto, ele forma alguma espécie de intenção comunicativa, um plano mental referente à modificação particular que deseja provocar. $\mathrm{O}$ problema para o falante é formular sua intenção de tal modo que o ouvinte deseje a modificação de sua informação pragmática como elaborada pelo falante. Para tanto, o falante tenta antecipar a interpretação que o destinatário possivelmente atribuirá à sua expressão lingüística. Postulamos que, nos discursos políticos, as expressões lingüísticas atributivas de capacidade são, por vezes, poderosos modalizadores deônticos que atuam no sentido de suscitar esse "desejo" por parte do ouvinte, ou seja, funcionam, persuasivamente, de modo a possibilitar o sucesso que o orador objetiva.

Da perspectiva do ouvinte, a interpretação que ele faz da expressão lingüística estará apenas em parte baseada na informação nela contida. Igualmente importante é a informação que o destinatário já possui e pela qual ele interpreta a informação lingüística. Do ponto de vista do falante, isso significa que a expressão lingüística não precisa ser uma verbalização plena da sua intenção.

Temos, assim, um modelo que nos permite investigar as expressões lingüísticas atributivas de capacidade como estratégia de modalização deôntica atuando qual mediadoras entre falantes e ouvintes, a serviço de intenções. 


\section{Tipologia das modalidades}

Parece haver um consenso entre lingüistas, dentre os quais citamos Lyons (1977), Halliday (1985), Goossens (1987), Hengeveld (1989), Dik (1989), no que concerne à caracterização das modalidades em dois tipos básicos: epistêmica e deôntica. A modalidade epistêmica refere-se ao eixo da crença, do conhecimento, e envolve, necessariamente, um julgamento do falante. A modalidade deôntica, por sua vez, diz respeito ao eixo da conduta, à linguagem das normas, do dever, daquilo que se deve fazer, aos valores de permissão, obrigação, volição.

Alguns lingüistas, no entanto, sustentam a idéia de que existe outro tipo de modalidade, além dos dois tipos básicos referidos no parágrafo anterior. Palmer (1986), por exemplo, postula a existência de uma terceira modalidade, a chamada dinâmica, que engloba as noções de capacidade/habilidade.

Assim, enquanto os modalizadores epistêmicos indicam o comprometimento do falante com relação àquilo que enuncia, os modalizadores deônticos indicam o grau de imperatividade ou facultatividade atribuído a um dado conteúdo proposicional. Por sua vez, as expressões atributivas de capacidade comporiam a modalidade dinâmica por, diferentemente da deôntica e da epistêmica, não perpassarem pelo crivo da subjetividade de quem enuncia (postulação sobre a qual iremos discutir logo mais), assim apenas assinalando uma capacidade/habilidade de outrem. Para efeito de melhor compreensão, seguem-se alguns exemplos:

01) O Presidente foi feliz em sua escolha, pois aquela mineração certamente vai gerar inúmeras divisas ao Estado e muito mais para o Brasil ${ }^{1}$.

Todos os trechos transcritos, que não estiverem seguidos por nota indicativa da fonte da qual foram extraídos, são retirados de discursos proferidos na Câmara dos Deputados, disponibilizados no endereço eletrônico oficial da Câmara, www.camara.gov.com.br. Em todos, haverá expressões em itálico. Os grifos são de nossa inteira responsabilidade. 
02) Precisamos construir uma alternativa à Esquerda deste Governo. (...) Não podemos deixar que as eleiçōes de 2006 se polarizem entre Fernando Henrique Cardoso ou José Serra e Lula, com a mesma política, com a mesma proposta, numa falsa polarização. $E^{\prime}$ necessária alternativa de Esquerda.

Percebemos que, no exemplo 01, o grau de comprometimento do enunciador em relação a seu enunciado é pleno, haja vista a escolha do advérbio de afirmação "certamente". Caso, em seu lugar, houvesse um advérbio de dúvida, como "talvez", por exemplo, a relação de comprometimento entre aquele que enuncia e aquilo que é enunciado seria significativamente menor. Temos, assim, um exemplo do uso de modalizadores epistêmicos. No exemplo 02, por sua vez, temos a instauração do valor semântico de obrigação por parte do enunciador mediante a utilização de verbos e de um adjetivo em posição predicativa. Os modalizadores deônticos indicam, no exemplo 02 , um alto grau de imperatividade atribuído pelo enunciador ao conteúdo proposicional.

No exemplo 03, logo abaixo, temos uma amostra do que Neves denominou ser a expressão mais estritamente alética de uma língua natural, ou seja, mais intimamente comprometida com a verdade relacionada a mundos possíveis, a saber: a atribuição de capacidade (física, mental ou intelectual).

03) eu perguntaria agora e vocês já poderiam responder... João... existe uma diferença... entre sociologia jurídica e sociologia do direito? (NEVES, 2002, p. 163).

Feita essa breve distinção entre modalidade deôntica, epistêmica e dinâmica e, antes de passarmos à discussão sobre a postulação da existência da modalidade dinâmica, dedicaremos o próximo tópico a uma breve consideração da modalidade deôntica. 


\section{A modalidade deôntica e sua manifestação}

Por modalidade deôntica, entendemos, com Lyons (1977, p. 823), que se trata da modalidade cuja preocupação é com a necessidade ou possibilidade de atos executados por agentes moralmente responsáveis, estando, assim, associada às funções sociais de permissão e obrigação. Desse modo, um enunciado deonticamente modalizado nos concede a descrição não de um ato propriamente dito, mas de um estado-de-coisas (concepção lingüisticamente codificada pela predicação que o falante faz de uma situação possível de ocorrer em algum mundo real ou imaginário Dik, 1997) que se efetivará se um ato em questão for realizado. Segundo Neves (1996, p. 193): “[...] isto se compreende facilmente, levando-se em conta que essa modalização diz respeito à conduta, que se projeta para momento posterior à manifestação do déon, isto é, da necessidade deôntica".

Quanto à manifestação da modalidade deôntica, destacamos, segundo Lyons (1977), que as sentenças deonticamente modalizadas procedem, tipicamente, de alguma fonte ou causa em que sempre há alguém ou alguma entidade que $\mathrm{X}$ reconhece como responsável por ele ser obrigado a exercer algum ato. Lyons chama de fonte deôntica a pessoa ou instituição que cria a obrigação ou permissão que recai sobre X, permitindo-lhe ou obrigando-o a executar algum ato. A pessoa ou instituição X sobre quem recai a obrigação é denominada alvo deôntico.

A fonte sempre instaura um valor deôntico (permissão, obrigação, proibição) e este valor, por sua vez, é expresso mediante um meio lingüístico (verbos auxiliares, verbos plenos, adjetivos em posição predicativa etc.). Ao instaurar um dado valor deôntico, o proferidor do discurso, que sempre enuncia de um lugar enunciativo determinado, ou seja, de uma posição sócio-histórica-ideológica reconhecida, pode optar por incluir-se ou excluir-se do alvo de incidência do valor deôntico instaurado, isso é o que chamamos em nossa pesquisa de comportamento quanto ao valor deôntico instaurado. Ainda está na opção do orador asseverar ou atenuar a força ilocucionária 
em relação ao valor deôntico instaurado. Todas essas opções se prestam a propósitos enunciativos específicos que trabalham no sentido de convencer a audiência das teses defendidas pelo orador.

Segue-se um trecho retirado de discurso político proferido na Câmara dos Deputados como ilustração dos conceitos supracitados:

03) Como mostra a ABIQUIM (Associação Brasileira da Indústria Química), praticamente todos os demais setores industriais dependem, de alguma forma, da indústria química, que fornece matérias-primas para quase tudo o que está a nossa volta. A agricultura também é fortemente dependente dos produtos químicos, sejam fertilizantes, sejam defensivos agrícolas, sejam materiais de embalagem. Trata-se, efetivamente, de uma indústria de base. É preciso, portanto, Srs. Deputados, que o Governo dê mais atenção ao setor, estimulando o seu crescimento. Só assim se poderá evitar que, no futuro, venhamos a assistir não apenas a um crescimento ainda maior das importações de produtos químicos, mas, ainda pior, ao aumento das importações de produtos de maior valor agregado, cuja produção local, sem o fornecimento de matérias-primas químicas produzidas localmente, pode perder sentido.

Assim, mediante a utilização de um adjetivo em posição predicativa (preciso), uma obrigação (valor deôntico) é instaurada pelo orador (fonte deôntica). Essa obrigação recai sobre o Governo (alvo deôntico). O parlamentar não se inclui na incidência do valor deôntico, pois se coloca à parte desse "Governo" que precisa conceder mais atenção à Indústria Química, afinal ele está a levantar a bandeira dessa causa, não é ele, portanto, a parte do Governo que precisa conceder essa atenção. Interessante notarmos que o trecho deonticamente modalizado é antecedido da constatação de ser a Indústria Química uma Indústria de base, portanto, fundamental 
aos demais setores do país, e precedido de uma sanção. O trecho modalizado é, portanto, a conclusão lógica a que se pode chegar diante das evidências elencadas, reforçada pela sanção - a perda futura de uma Indústria tão essencial.

Vejamos, agora, mais um trecho que ilustra a manifestação da modalidade deôntica no discurso político:

04) Se o Estado abriu a estrada e a entregou ao público, é sua responsabilidade prover a sua conservação em condições, pelo menos, mínimas, para garantir a integridade física dos usuários e veículos.

Nesse segundo trecho, notamos que, mediante a utilização do substantivo (responsabilidade), uma obrigação (valor semântico) é instaurada pelo orador (fonte deôntica). Essa obrigação recai sobre o Estado (alvo deôntico). O orador não se inclui na incidência do valor deôntico por ele instaurado.

\section{Rediscutindo a modalidade dinâmica}

Alguns lingüistas, como Palmer (1986); Sweetser (1990) e Bavin (1995), sustentam a idéia de uma outra modalidade, além dos dois tipos básicos: epistêmica e deôntica. Analisemos, sucintamente, como alguns estudiosos se posicionam em relação a essa terceira modalidade.

Palmer (1986), por exemplo, postula a existência de uma terceira modalidade, chamada dinâmica, a qual engloba as noções de capacidade/habilidade. Halliday (1985), por sua vez, não considera a modalidade dinâmica como um tipo específico de modalidade, ele a chama de potencialidade.

Assim, enquanto, para Palmer, o enunciado "John can do it" ("João pode fazer isto") é uma expressão dinamicamente modalizada, 
para Halliday, é uma expressão que indica potencialidade, pois indica ser possível a João fazer algo, haja vista ser ele possuidor de habilidade. Para Halliday, nessa situação, o verbo "poder" não seria considerado como epistêmico (Ex: "Você pode entrar agora [ou mais tarde]" possibilidade epistêmica) ou deôntico (Ex: "Você pode entrar agora [eu permito]" - permissão deôntica) por constituir apenas uma noção de habilidade/ capacidade e não ter relação direta com a avaliação ou julgamento do falante.

Palmer concorda com Halliday em parte, ou seja, aceita que as expressões dinamicamente modalizadas não têm relação direta com a avaliação ou julgamento do falante. Por isso mesmo, Palmer tenta incluir em seus estudos da modalidade os casos em que os modais não expressam a atitude subjetiva do falante, e, portanto, não são considerados como deônticos ou epistêmicos. Para Palmer, modais como can e will são orientados para o sujeito, pois dizem respeito à habilidade deste sujeito, e não a uma opinião. Desse modo, o argumento de Halliday para a não aceitação da existência da modalidade dinâmica, conforme postulada por Palmer, é utilizado por este exatamente para justificar esse terceiro tipo de modalidade.

Sweetser (1990) também considera a modalidade dinâmica distinta da modalidade deôntica e da epistêmica. Segundo a autora, seus significados referem-se à habilidade e à disposição, não podendo, por suas próprias naturezas, serem impostos por alguém ou por outra instituição qualquer.

Entretanto, alguns autores englobam os valores deônticos e a habilidade/capacidade em uma única categoria, fazendo distinção entre modalidade epistêmica e modalidade de raiz ( $\mathrm{O}$ termo modalidade de raiz compreende todos os usos não epistêmicos dos verbos modais. Foi utilizado pela primeira vez por Hofmann em 1966 apud Palmer, 1986). Silva-Corvalán (1995, p. 75) afirma usar o termo modalidade de raiz para abarcar as categorias deôntica e dinâmica da lógica modal, ou seja, englobando obrigação, necessidade, permissão e habilidade. 
Ferreira (2000), em concordância com Silva-Corvalán, opta por englobar as noçōes de obrigação e permissão (as tradicionais noçōes deônticas) e capacidade. Também chama de modalidade de raiz a categoria que compreende todos os usos não epistêmicos dos verbos modais.

Parece-nos discutível a postulação de Halliday, aceita por Palmer, sobre a existência de expressões, em línguas naturais, vinculadoras das noções de habilidade/ capacidade destituídas de relação direta com a avaliação ou julgamento do falante. Achamos que essa aparente falta de vinculação se dá em virtude de as exemplificações concedidas pelo autor estarem descontextualizadas; esse parece ser o grande problema. Ao nos depararmos com o enunciado "John can do it", é indiscutível estarmos diante de uma expressão atributiva de habilidade/ capacidade, mas inserida em um discurso efetivamente realizado, o verbo "can", presente nessa expressão, poderia ser considerado um verbo epistêmico ou um deôntico.

Suponhamos a conversa entre um médico e a mãe de um jovem que acaba de submeter-se a uma intervenção cirúrgica. A mãe então pergunta acerca das possibilidades locomotoras de seu filho, ao que o médico responde: "João pode andar, só depende dele”. Está implícito nesse diálogo que João pode ou não andar. A fala do médico parte do eixo da crença, do seu conhecimento de um dado estado de coisas, envolve o seu julgamento sobre a probabilidade de ocorrência do estado de coisas em questão. O verbo "can", nesse caso, é epistêmico. Temos, portanto, a nosso ver, uma expressão atributiva de capacidade epistemicamente modalizada.

Imaginemos, agora, que a expressão "João pode fazer isso" esteja inserida em um discurso político. Imaginemos o seguinte contexto: um parlamentar discursa acerca da necessidade urgente de se destinar mais verbas à educação infantil. Em um determinado momento, volta-se para o Ministro da Educação, suponhamos que seu nome seja João, e diz: "João pode fazer isso". Ora, essa expressão 
tem enorme poder persuasivo, à medida que, ao exaltar a capacidade daquele que está sendo chamado à ação, instaura uma obrigação. É, assim, a nosso ver, uma expressão atributiva de capacidade utilizada deonticamente. Não lhe parece muito íntimo o modo como um parlamentar se referiu, durante um discurso, ao Ministro?

Parece-nos evidente a improbabilidade de o enunciado se manter como uma asserção descompromissada das intenções e das necessidades do falante que assevera, portanto difícil é aceitar a existência de enunciados despossuídos de traços de subjetividade. Acreditamos que o exemplo que se segue, extraído do discurso proferido pelo Sr. Maurício Rabelo, deputado federal eleito pelo Partido Liberal, representando o Estado de Tocantins, corrobora empiricamente nossos motivos supracitados:

05) Ministro Alfredo Nascimento, está em suas mãos a decisão de terminar aqueles 30 quilômetros que significam economia muito grande para todo o povo de Goiás, do Tocantins, do Maranhão, do Pará e do Piauí.

O contexto do qual extraímos o excerto nos mostra claramente que a atribuição de capacidade conferida pelo enunciador àquele a quem se dirige em plenário é uma imposição de tarefa, o que torna o ministro Nascimento o alvo da obrigação deôntica instaurada por Rabelo (fonte deôntica). A noção de obrigatoriedade é confirmada pelo apelo moral feito logo em seguida, quando o orador expõe não apenas os transtornos pelos quais aqueles que precisam do trecho de estrada inacabada passam, mas também levanta suspeitas acerca do possível desvio de verbas destinadas à obra em questão.

Consideramos, dessa forma, não ser coerente a postulação de um terceiro tipo de modalidade para compreender as expressões atributivas de habilidade/ capacidade, nem tampouco incluir essas expressões juntamente à modalidade deôntica sob o rótulo de 
modalidade de raiz, como fizeram Silva-Corvalán (1995, p. 75) e Ferreira (2000), separando-as de expressões epistêmicas. O que sugerimos é a avaliação das expressões lingüísticas em contextos efetivos de interação pela linguagem verbal.

Embora Neves (1996, p. 171-172) não fale explicitamente em trechos dinamicamente modalizados como recursos de modalização deôntica, aos quais a existência e função acabamos de exemplificar, nela encontramos respaldo para nossa postulação. Ao versar sobre os diversos tipos de modalidade (alética, deôntica e epistêmica) e citar que a expressão mais estritamente alética, numa língua natural, ou seja, comprometida com a verdade relacionada a mundos possíveis, é a de capacidade (física, moral ou intelectual), cita a autora que casos de sentenças que sejam apenas aleticamente modalizadas são pouco claros no discurso comum e que uma investigação sobre o valor puramente alético de uma proposição a retiraria do contexto de enunciação para centrar-se na organização lógica interna de seus termos e na relação que ela mantém com os mundos possíveis nos quais seria, ou não, verdadeiros.

O mesmo entendimento encontramos em Koch (2004, p. 135). Ou seja, ao declarar a autora que os modalizadores aléticos são pouco comuns em textos da língua natural, por se confundirem geralmente com os epistêmicos ou os deônticos, uma vez que ou nos referimos ao conhecimento que temos a respeito dessa experiência ou à sua obrigatoriedade/facultatividade, Koch respalda a necessidade precípua de análise contextual que defendemos. É mediante esse tipo de análise que propomos aqui a interpretação de trechos dinamicamente modalizados como recursos de modalização deôntica. Assim, nossa postulação, nossa no sentido de não a termos explicitamente encontrado nos autores pesquisados, é proveniente do que podemos depreender das ponderações das duas supracitadas autoras e da análise que realizamos de discursos proferidos na Câmara dos Deputados. 


\section{As construções atributivas de capacidade como recurso de modalização deôntica e a construção da persuasão em discursos políticos}

A fim de avaliarmos a relevância do tema a que nos propomos investigar, a saber: a modalização deôntica no discurso político, realizamos pesquisa piloto na qual discursos proferidos em várias Sessões Ordinárias e Extraordinárias proferidas na Câmara foram analisadas. Durante esse empreendimento, chamounos a atenção a predileção por parte de alguns oradores no que concerne à instauração do valor semântico de obrigação, mediante a utilização de expressões atributivas de capacidade. Assim, registramos as ocorrências dessas expressões lexicais da modalidade deôntica e as confrontamos com outros meios lingüísticos de expressão dessa modalidade, também instauradores de obrigação, e, mediante o confronto dos contextos nos quais umas e outras se acham inseridas, podemos chegar a um entendimento do papel das expressões atributivas de capacidade na construção da persuasão em discursos políticos.

Ao analisarmos o uso de expressōes lingüísticas deonticamente modalizadas na construção da persuasão em discursos proferidos em Sessões Ordinárias e Extraordinárias da Câmara dos Deputados, constatamos que a utilização de tais expressões produz efeito de sentido de grande valia à persuasão, uma vez que instaura valores de obrigação como pano de fundo, sobressaindo, em primeiro lugar, a imagem positiva, criada pelo orador, da competência daquele que está sendo instado a agir. A escolha de uma expressão atributiva de capacidade em lugar de um outro meio lingüístico de expressão da modalidade deôntica (Ex: verbo auxiliar modal seguido de infinitivo - "Tem-se que dar um basta a isso. Os partidos têm que ter total autonomia, e não se trata de impedir sua fundação".) é muito significativa, enquadrando-se no que Barros (2002, p. 197-198) chama de estratégia persuasiva de sedução. Ou seja, a fim de manipular o alvo sobre o qual recai o valor deôntico instaurado, o orador opta por 
enaltecer os brios daquele que está sendo instado à realização de ação ao fornecer, publicamente, uma imagem positiva da competência do alvo sobre o qual incide o valor deôntico. Analisemos os trechos que se seguem, a fim de constatarmos o que estamos a expor.

05) Ministro Alfredo Nascimento, está em suas mãos a decisão de terminar aqueles 30 quilômetros que significam economia muito grande para todo o povo de Goiás, do Tocantins, do Maranhão, do Pará e do Piauí.

06) [...], o Ministério da Educação deve implantar rigor maior e critério adequado na autorização de novos cursos [...] Sr. Presidente, o Ministério da Educação tem de provar a todos que trabalhamos com educação que tem competência para fazer o que não está fazendo adequadamente.

No trecho 05 , ao trazer à tona a problemática de 30 quilômetros de estrada inacabada da $\mathrm{Br}-080$, em Goiás, o deputado Rebelo opta pela instauração do valor deôntico de obrigação mediante a utilização de expressão atributiva de capacidade. O contexto do qual esse trecho foi extraído nos mostra claramente que se trata de imposição de obrigação, haja vista o orador questionar a própria honestidade dos responsáveis pela obra está em jogo.

Tendo em vista que toda opção lingüística do orador por ocasião da instauração em seu discurso de um dado valor deôntico se dá em função da tentativa de obtenção da adesão da audiência, por que o Deputado Rebelo optou pela instauração de obrigação através de uma expressão atributiva de capacidade? Uma forte justificativa para a opção lingüística do orador diz respeito ao fato de o Ministro dos Transportes, Alfredo Nascimento, pertencer ao mesmo partido do Parlamentar que o chama à ação, 
a saber: Partido Liberal, segundo o próprio Deputado Rebelo explicita em seu discurso.

Percebemos, em nossa análise, que, quando o proferidor do discurso chama à ação alguém de seu mesmo Partido ou alguém de Partido aliado ao seu, em dada discussão, há a opção pela instauração de obrigação mediante o recurso da expressão atributiva de capacidade, pois esta atua qual atenuante do desgaste comumente gerado entre aquele que chama à ação e aquele que é chamado à ação, uma vez que, como já mencionamos, tal estratégia apresenta, em primeiro plano, um elogio, deixando a obrigação como pano de fundo.

Confrontemos agora a expressão lingüística instauradora de obrigação selecionada pelo orador do trecho 05 com a escolha feita pelo orador do trecho 06.

No trecho 06, a instauração de obrigação faz-se mediante verbos auxiliares modais (dever, ter de) seguidos de verbos no infinitivo (implantar, provar). Percebemos, em nossa análise, que oradores de partidos que se opõem ante certas temáticas, tendem a optar pelo não uso de expressões atributivas de capacidade. Assim, instauram o valor de obrigação mediante outros meios lingüísticos de expressão da modalidade deôntica, meios esses que instauram a obrigação em primeiro plano, ao mesmo tempo em que, como pano de fundo, emitem uma imagem positiva acerca do instaurador da obrigação. No caso específico do discurso do Sr. Irapuan Teixeira, a "superioridade" de sua pessoa pública é explicitada ao detrair o orador a imagem do Ministro da Educaçăo, logo no início de seu discurso.

A ênfase nas férias do Ministro, bem como a troca de Chefes de Gabinete, evocada como excessiva pelo Sr. Irapuan, conferem respaldo ao instaurador de obrigações. Não nos surpreendeu o fato de o Ministro da Educação c o orador serem membros de Partidos distintos.

Prossigamos com mais uma análise. Segue-se, agora, um trecho do discurso do Deputado Mauro Benevides, PMDB-CE. 
08) Arrisco-me a fazer esse vaticínio nesse instante, $\mathrm{Sr}$. Presidente, porque acredito no voder de argumentação do Senador Romero Jucá, que possui amplas condiçōes de convencer o Ministro Antônio Palocci a rever aqueles números da receita e chegar a um indicador que permita assegurar aos Estados a importância de 5 bilhões e 200 milhōes de reais para cobrir os prejuízos da Lei Kandir [...]Espero também que o relator, som a competência habitual, revelada ao longo de sua vida pública, consiga avançar, como prometeu o Presidente da República, no sentido de que o salário mínimo tenha sua vigência iniciada nāo em $1^{\circ}$ de maio, mas sim em $1^{\circ}$ de março do próximo ano [...] O relator Romero Jucá possui, indiscutivelmente, engenho e arte, ?, mais do que isso, competência bastante para buscar os recursos que ofereçam suporte a essa inovaçāo, que entendi do meu dever sugerir neste momento à sompetente Comissão do Orçamento.

São dois os objetivos do discurso proferido pelo Deputado Benevides: assegurar a cinco Estados da Federação a importância de 5 bilhōes e 200 milhões de reais para cobrir os prejuízos da Lei Kandir e ter a vigência do salário mínimo iniciada em $1^{\circ}$ de março do próximo ano. Ambos os objetivos recaem sobre a pessoa do Relator do Orçamento, Senador Romero Jucá.

Chamou-nos a atenção, ao longo de todo o discurso, a quantidade de expressões atributivas de capacidade utilizadas pelo orador. Postulamos serem todas elas recursos de modalização deôntica, uma vez que o contexto na qual estão inseridas traz à tona o dever cívico para com a restituição das perdas que a Lei Kandir acarretou aos Estados do Rio Grande do Sul, São Paulo, Pará, Bahia e Mato Grosso e para com o trabalhador brasileiro. A competência tanto do Relator quando da Comissão do Orçamento é tão veementemente enfatizada que o fracasso de ambos implicaria invalidar essa tão evocada competência. Digno de nota é o fato de o 
Relator pertencer ao mesmo partido político do orador que o chama a agir, PMDB, portanto, mecanismo mais adequado, pois atenua a instauração de obrigação.

\section{Palavras concludentes}

Percebemos que as opções lingüísticas instauradoras de obrigação feitas pelos oradores de discurso políticos se prestam a funçōes distintas. Enquanto as expressōes atributivas de capacidade instauram obrigações de modo a atenuar a inconveniência de chamar à ação um membro do mesmo partido político, as demais expressões lingüísticas instauradoras de obrigação são muito mais imperativas, pois instauram obrigação em primeiro plano. Enquanto as primciras conferem ao orador e ao alvo sobre o qual recai o valor deôntico, instaurando imagens positivas, as segundas põem em relevo a imagem positiva apenas do orador.

Cumpre esclarecer que os meios lingüísticos de expressão da modalidade são vários. Koch (1986) cita, dentre outros, os auxiliares modais, as formas verbais perifrásticas, os advérbios de modalidade, as orações ou expressão modalizadoras. Desta feita, consideramos que a modalidade deôntica pode ser expressa por verbos auxiliares modais e plenos, adjetivos em posição predicativa, substantivos, advérbios e por expressōes atributivas de capacidade. Neste trabalho, analisamos o papel de tais expressōes que, embora destituídas das marcas lingüísticas de modalização mais características, são importantes recursos de modalização deôntica.

Defendemos que um discurso acentuadamente marcado pelo uso de meios lingüísticos de expressão da modalidade deôntica, como o é o discurso político, escolhe e articula esses meios para alcançar os fins a que se propōe. Desse modo, a compreensão das nuances significativas dessas expressōes será de suma relevância à aproximação eficaz, quer como produtores, quer como leitores, desse que é um discurso fundamental à construção da cidadania. 


\section{Referências}

BAVIN. Edith L. The obligation modality in Western Nilotics languages. In: BYBEE, J. L.; FLEISCHMAN, S. (eds.) Modality in grammar and discourse. Amesterdam, Philadelphia, v.32, 1995.

DICK, C. S. The theory of funcional grammar. Pt.I: The Structure of the clause. Dorderecht-Holland/Providence RI-EUA: Foris Publications, 1989.

. The theory of funcional grammar. Pt.II: Complex and derived constructions. New York: Mounton, 1997.

Discursos proferidos em Sessões realizadas na Câmara dos Deputados, nos dias 30 de junho, 05 de julho, 12 de julho e 27 de dezembro de 2004. Disponibilizados no endereço <www.camara.gov.com.br >.

FERREIRA, Lúcia Maria Alves. A estabilidade semântico-sintática do modal Poder: evidências em três sincronias. Tese (Doutorado), Universidade Federal do Rio de Janeiro, Rio de Janeiro, 2000.

GIVÓN, T. Functionalism and Grammar. Amsterdam/Filadélfia: John Benjamins Publishing Company, 1995.

GOOSSENS, F. M. Modality and modals: a problem for functional grammar. In: BOLKESTEIN,A. M.; GROOT, C. de; MACKENZIE, J. L. (eds.) Predicates and terms in functional grammar. Dordrecht, 1987.

HALLIDAY, M. A. K. An introduction to functional grammar. Baltimore: Edward Arnold, 1985.

Arnold, 1973.

Explorations in the functions of language. Londres: Edward

HENGEVELD, K. Layers and operators in Functional Grammar. Journal of Linguistics, v.25, 1989. 
KOCH, I. G. V. A questão das modalidades numa nova gramática da língua portuguesa. Estudos lingiiísticos, Araraquara, 1986.

. Introdução à lingiiística textual. São Paulo: Martins Fontes, 2004.

LYONS, J. Semantics. Cambridge University Press, 1977.

NEVES, M. H. M. A Modalidade. In: KOCH, I.. V.(org). Gramática do vortuguês falado: desenvolvimentos. v. 6. Campinas-SP: UNICAMP, 1996.

- A Modalidade. In ABAURRE, Maria Bernadete M.; RODRIGUES, Ângela C. S. (orgs.) Gramática do Português Falado, vol. VIII: Novos estudos descritivos. São Paulo: Unicamp, 2002.

PALMER, F. R. Mood and modality. New York: Cambridge University Press, 1986.

SILVA-CORVALÁN. Carmem Silva. Contextual conditions for the interpretation of "poder" and "deber" in Spanish. In: BYBEE, J. L.; FLEISCHMAN, S. (eds.) Modality in grammar and discourse. V. 32. Amsterdam, Philadelphia, 1995.

SWEETSER, Eve. From etymology to pragmatics: metaphorical and cultural aspects of semantic struture. Cambridge: Cambridge University Press,
1990.

THOMPSON, S. That-Deletion from a discourse perspective. V.13. Berkeley Linguistics Society, 1987. 